\title{
Stabilization to prevent soil erosion using vetiver (Chrysopogon zizanioides L.) in slopes: a field case study of selected grounds at Guatemala
}

\author{
E. Garzón ${ }^{1 *}$, Flor M. González-Miranda ${ }^{2}, J$. Reca $^{1}$, and P.J. Sánchez-Soto ${ }^{3}$ \\ ${ }^{1}$ Departamento de Ingeniería, Universidad de Almería, La Cañada de San Urbano - 04120 - Almería, Spain \\ ${ }^{2}$ Escuela de Ingeniería Mecánica Industrial, Facultad de Ingeniería, Universidad de San Carlos, Guatemala \\ ${ }^{3}$ Instituto de Ciencia de Materiales, Centro Mixto CSIC - Universidad de Sevilla. Avda. Américo Vespucio 49, Isla de la Cartuja - \\ 41092 - Sevilla, Spain
}

\begin{abstract}
The effects of Chrysopogon zizanioides (vetiver) on the hydrophysical properties of soils and infiltration rate have been determined. Thus, it has been examined the stabilization to prevent soil erosion using vetiver in slopes, studying a field case of selected grounds at Guatemala. The particle size analysis of the soil samples showed a predominant sand fraction and a plasticity index of $7.9 \%$. The results indicated that these soils were fairly acid with worthless salinity and non-swelling. The specific surface area, determined by nitrogen adsorption-desorption analysis, ranged from $11.7-15.5 \mathrm{~m} 2 / \mathrm{g}$ and the pore sizes between $17-160 \mu \mathrm{m}$, which changed to $20-100 \mu \mathrm{m}$, with predominant pore size around $40 \mu \mathrm{m}$ after cultivation. The characteristics of the soils showed the presence of cohesion $(2.05 \mathrm{t} / \mathrm{m} 2)$ and an internal friction angle $\Phi=31.69^{\circ}$. After the plantation, it has been found a decrease in the cohesion and an increase of the internal friction angle. The sowing of vetiver affected the infiltration characteristics of the soil. An analysis using the Kostiakov-Lewis classical model, with a mathematical fitting, has been performed. From these results, it has been deduced that the slope protected using this plant diminished its infiltration rate, being associated to the compaction caused by the plant roots. The present results demonstrated that the plantation of vetiver is effective to stabilize and prevent slopes from the soil erosion caused by severe rainfall events.
\end{abstract}

\section{Introduction}

The plant Chrysopogon zizanioides $L$. has been used to the improvement of contaminated soils with heavy metals, for instance in India [1,2] and Thailand [3], or diesel polluted soils in Israel [4]. Different treatments of fertilization, following this methodology of phytoremediation, have been applied in China in soils affected by the contamination of mines activity [5]. Concerning this subject of investigations, Dahn et al. [6] observed that there was other species more effective in the treatment of heavy metals, although these had the capacity to progress in extreme conditions and quite efficient in the biodegradation of organic wastes. In Latin-American countries, several plants have been studied with the same purpose, such as vetiver grass (Chrysopogon Zizanioides) and foraged peanut, bamboo and native trees with cohesive roots to decrease the erosion [7].

Grimshaw and Helfer [8] reviewed the use of vetiver for soil and waste conservation, land rehabilitation and embankment stabilization. Wilde et al. [9] reported that the fertilization of the cultivation improved the extraction of heavy metals from the soils. Demirel and Demirel [10] and Robles-Austriaco et al. [11] reported the use of vetiver to prevent and reduce the erosion in soils studied in Turkey and Philippines. Mckovski and van Beek [12] studied the root morphology and effects on soils reinforcement and slope stability of Vetiver, with the plants grown in a semi-arid climate. They reported the effects of this plant to reduce contamination and to decrease the erosion, studying the evolution of parameters such as cohesion and internal friction. There are reports that studied the conditions of development of vetiver to prevent the erosion of contaminated soils by heavy metals $[1,12]$.

New methodologies have been applied, such as finite elements to investigate vetiver root in geotechnical structures with experiments and analysis using this plant [13]. It was studied the evolution of the shear stress of a soil with the development of vetiver using a plasticelastic model [13]. Srivastava et al. [14] conducted a research on a sustainable ecological approach on affected soils of a coal mining area with fly ash and selective plantation. Balangood et al. [15] studied the development of vetiver in earth slopes of Philipines and found that this plant has capacity of aggregation. Thus, taking into account the precedent investigations, the objective of the present work was to evaluate the feasibility of the application of bioengineering tools, such as the use of Chrysopogon Zizanioides (vetiver), for slope stabilization and in order to prevent soil from erosion in selected grounds in Guatemala. 


\section{Material and methods}

\subsection{Soils under study}

The experiment started with the plantation of vetiver grass. A selected slope in the Villalobos river basin, located in the vicinity of the University of San Carlos de Guatemala was selected. The slope was divided into two similar experimental units. The plantation of the vetiver grass was conducted in one of these units whereas the other one was left unplanted to serve as control unit. A total of 75 plants were planted in 3 lines of 25 plant with a spacing of $0.5 \mathrm{~m}$ among plants. (Figure 1). The slope angle was approximately $40^{\circ}$ for both units. The soil of the units was sandy with low fractions of clay and gravel. Representative soil samples of these units were taken for a more detailed study. These samples were denoted as DVH2 and HSF, without and with vetiver, respectively.

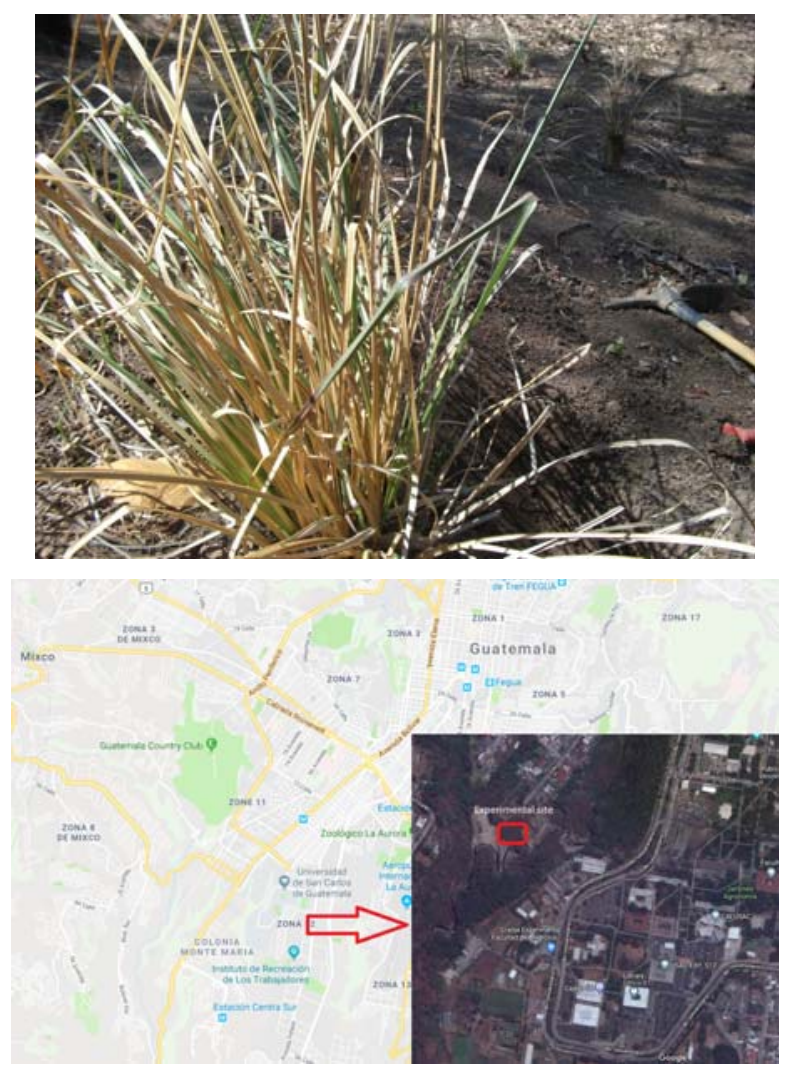

Fig. 1. Plantation of Chrysopogon Zizanioides L. on a slope near Universidad de San Carlos in the terrains where the present study was conducted.

\subsection{Mineralogical study}

The mineralogy of the samples was studied by X-ray Diffraction (XRD) analysis. An X'PERT PRO X-ray diffractometer (PANalytical B.V. Germany), was used at $36 \mathrm{kV}$ and $26 \mathrm{~mA}$ settings, with $\mathrm{Ni}$-filtered $\mathrm{CuK} \alpha$ radiation and graphite monochromator. Oven-dried samples were prepared for XRD testing by a gently ground in an agate mortar. Random-oriented and oriented powder mount specimens using deionized water and ethyleneglycol vapour were prepared. The XRD instrument, with $\mathrm{X}^{\prime}$ Celerator detector, had the following settings: $2 \theta$ range of $3-70^{\circ}$; step size of $0.03^{\circ}\left({ }^{\circ} 2 \theta\right)$; scan speed of $0.05 / 240 \mathrm{~s}(2 \theta / \mathrm{s})$; counting time of $240 \mathrm{~s}$; divergence slit of $1 / 2\left({ }^{\circ} 2 \theta\right)$ and antiscatter slit of $1 / 4$ $\left({ }^{\circ} 2 \theta\right)$.

The identification of crystalline phases using the diagnostic peaks of each mineral phase, according to the files by the Joint Committee for Powder Diffraction Standards, was performed using the software (SICOMP PC 16-20 System) provided by the equipment.

\subsection{Parameters of soil analysis}

The following parameters of interest have been considered in soil analysis at the laboratory: determination of electrical conductivity, $\mathrm{pH}$, soluble salts, gypsum content, $\mathrm{CaCO}_{3}$ content, organic matter and cationic exchange capacity of the original and sowing soil, following the experimental protocols described by Marañés et al. [16].

\subsection{Surface area and pore size distribution}

An equipment ASAP 2010 for nitrogen adsorption was used. Specific surface areas were estimated by BET (Brunauer-Emmett-Teller) and Langmuir models along the adsorption branch $[17,18]$. The pore size distribution was estimated following the Barrett, Joyner and Halenda (BJH) method [19].

\subsection{Geotechnical properties}

The geotechnical properties have been performed on the soils before and after the sowing of vetiveria at several times. The particle size analysis of the samples was performed using the ASTM D6913-04 [20]. The liquid and plastic limits, and plasticity index have been determined using the ASTM D4318-05 [21].

Cohesion and internal friction angles as geotechnical properties have been also determined using the ASTM D3080-98 [22].

\subsection{Infiltration tests and modellization (7)}

In order to compare the effect of the plant on the water infiltration into the soil, two infiltration tests were conducted both in the bare soil plot and the plot covered with the plant. Infiltration tests were performed using a double ring infiltrometer [23] in order to accurately measure the vertical infiltration. The measurement was carried out according to measurement standards (DIN 19682). Both cylinders were inserted $5 \mathrm{~cm}$ vertically into the soil and then they were both filled with a water sheet. The depth of water infiltrated was measured in the inner cylinder whereas the outer ring limits the lateral spread of water after infiltration. Time was register with a chronometer and the depth of water above the soil was measured using a measuring rod.

The measuring started by noting the time and the water level in the inner ring (reference level). When a 
specific depth of water was infiltrated, water was poured into the inner ring to refill the water layer to the initial level, so the water head remained almost constant during the infiltration test.

The results of the tests were adjusted to the classical Kostiakov-Lewis empirical model [24, 25]. The Kostiakov-Lewis model [24, 25] has been widely used to characterize the infiltration in agricultural soils.

It is emphasized that the equation resultant of the application of this model depends of the empirical parameter $\mathrm{K}\left(\mathrm{cm} \cdot \mathrm{min}^{-\mathrm{n}}\right)$, and with $\mathrm{n}$ values lower than 1 . The empirical parameter $\mathrm{f}\left(\mathrm{cm} \cdot \mathrm{min}^{-1}\right)$ is the infiltration rate for permanent conditions. The Kostiakov-Lewis equation is given in equation (1):

$$
I_{a}=K \cdot t^{n}+f \cdot t
$$

In this equation, $I_{a}$ is the infiltration $(\mathrm{cm})$ and $t$ is the time (min). The adjustment of the three empirical parameters ( $\mathrm{K}, \mathrm{n}$ and $\mathrm{f}$ ) in equation (1) was made by performing a non-linear regression using the least squares method.

\section{Experimental results and discussion}

\subsection{Mineralogical analysis}

The XRD technique allowed the identification in several representative soil samples of quartz and iron oxides, mainly hematite and the hydrated iron oxide maghemite; minerals of the feldspars group were also identified, possibly albite. The main minerals found in these samples were kaolinite, metahalloisite, illite and chamosite. A hydroxylated silicate mineral of the amphibole group, named riebeckite with chemical formula $\mathrm{Na}_{2}(\mathrm{Fe}, \quad \mathrm{Mg})_{3} \mathrm{Fe}_{2} \mathrm{Si}_{8} \mathrm{O}_{22}(\mathrm{OH})_{2}$, was also identified by XRD analysis. It is also detected the presence of some relative proportion of amorphous material (associated to a characteristic background of the XRD diagrams).

According to the findings of this mineralogical analysis, the present work is the first report on the identification of the amphibole riebeckite (being crocidolite a variety of this mineral), as found in some selected soils in Guatemala. However, it was not possible to compare with other XRD results on soils in that country due to an absence of previous published results and analysis using XRD.

The XRD diagrams of the oriented samples treated with ethyleneglycol vapours and the corresponding analysis demonstrated that swelling minerals of the smectite group are not present. Then, it can be classified as non-swelling clay soil samples.

Finally, as expected, the changes observed by XRD comparing the samples without and with vetiver are not relevant, even after 12 and 16 months of sowing the plant.

\subsection{Chemical and physical analysis}

Table 1 shows the main chemical and physical parameters of two selected soil samples. The $\mathrm{pH}$ of these samples is in the range 5-6, being soils fairly acid [16]. The sowing of vetiver cause a slight change in the $\mathrm{pH}$ values, with an increase to low basic values (5.97-6.27). This change could affect the solubility of some elements, such as potassium, and possibly it favours a higher mineralisation of the organic matter. It can be associated with the influence of rains in the time period under study.

The soil acidity or the loss of this characteristic is not a problem, because vetiver presents a development in a wide $\mathrm{pH}$ range of 3-10.5 as reported in the bibliography [1]. The contents of soluble salts, gypsum and sulphates, are very low. However, it can be also observed an increase of the sulphates after the sowing of vetiver. The electrical conductivity was found lower than $2 \mathrm{dS} / \mathrm{m}$, being an indication of their worthless salinity. The contents of organic matter are low with normal values of $2 \%$ in soil sample DVH2 to relatively high, $4 \%$, in sample HSF. When the sowing of vetiver is studied, the levels of organic matter are similar.

Table 1. Chemical parameters of soil samples from Guatemala.

\begin{tabular}{|c|c|c|c|c|c|}
\hline Crop & Soil & pH & $\begin{array}{c}\text { Electrical } \\
\text { conductivity } \\
(\mathrm{dS} / \mathrm{m})\end{array}$ & $\begin{array}{c}\text { Soluble } \\
\text { salts } \\
(\%)\end{array}$ & $\begin{array}{c}\text { Gypsum } \\
(\%)\end{array}$ \\
\hline No & DVH2 & 5.89 & 0.5 & 0.03 & n.d. \\
\hline No & HSF & 6.04 & 0.71 & 0.04 & n.d. \\
\hline Yes & & 6.27 & 0.30 & 0.02 & 0.0 \\
\hline \multirow[t]{2}{*}{ Yes } & & 5.97 & 1.98 & 0.12 & 0.0 \\
\hline & & $\underset{(\mathrm{mg} / \mathrm{l})}{\text { Sulphate }}$ & $\begin{array}{c}\mathrm{CaCO}_{3} \text { eq. } \\
(\%)\end{array}$ & $\begin{array}{c}\text { Organic } \\
\text { matter } \\
(\%)\end{array}$ & $\begin{array}{c}\text { Capacity of } \\
\text { exchangeable } \\
\text { cations } \\
(\mathrm{meq} / 100 \mathrm{~g} . \\
\text { soil) }\end{array}$ \\
\hline No & DVH2 & n.d. & 0.0 & 2.0 & 151.7 \\
\hline No & HSF & n.d. & 0.0 & 4.2 & 191.7 \\
\hline Yes & & 3.5 & 0.0 & 2.41 & 10.61 \\
\hline Yes & & 33.5 & 0.0 & 2.6 & 15.9 \\
\hline
\end{tabular}

n.d.: Not detected.

Finally, the values of cationic exchange capacity of the soils change from high (152-192) to low values (11-16) under the action of the sowing of the plant. According to these parameters, it is a very fertile soil for the development of the plant.

\subsection{Textural analysis by nitrogen adsorption- desorption}

The values of specific surface areas deduced by nitrogen adsorption and average pore sizes are included in Table 2. The original sample DVH2 shows a specific surface area (in $\mathrm{m}^{2} / \mathrm{g}$ ) of 15.50 (BET) and 21.25 (Langmuir); the sample HSF shows values slightly lower, 11.68 (BET) and 16.04 (Langmuir). In these samples, the values of specific surface areas determined by nitrogen adsorption using the Langmuir model are higher than using the BET model. Using the simplified method of Dolinar [26] for determining the external specific surface area of nonswelling fine grained soils, as in the present case (see 3.1. Mineralogical analysis), the calculated value for sample HSF is close to the experimental BET value. With cultivation, the values of specific surface areas of the sample did not change. 
Table 2. Specific surface areas and average pore size of soil samples without cultivation and with cultivation.

\begin{tabular}{|r|rrr|rr|}
\hline Sample & & \multicolumn{2}{|c|}{ Specific surface $\left(\mathrm{m}^{2} / \mathrm{g}\right)$} & \multicolumn{2}{r|}{ Pore size $(\mu \mathrm{m})$} \\
& & & Dolinar, & Ads & Desop \\
& BET & Langmuir & 2012 & & \\
\hline HSF & 11.68 & 16.04 & 10.57 & $1.97-$ & $1.99-$ \\
(SC) & & & & 103.92 & 101.48 \\
DVH2 & 15.50 & 21.25 & 10.57 & $1.97-$ & $2.06-$ \\
(SC) & & & & 100.33 & 105.59 \\
280 & 11.93 & 16.44 & & $1.97-$ & $1.98-$ \\
(CC) & & & & 115.26 & 102.59 \\
\hline
\end{tabular}

Note: $\mathrm{SC}=$ without cultivation $\mathrm{CC}=$ with cultivation

The average pore sizes of both soil samples HSF and DVH2 are around $100 \mathrm{~nm}$ (adsorption and desorption). The pore size density function of the original samples shows that the major part of the pores of the sample HSF was in the range $21.88-148 \mathrm{~nm}$ (Figure 2). Similar values were found for the sample DVH2, in this case ranging between 17.39-160.28 $\mathrm{nm}$. With cultivation, the major part of the pore sizes was observed in the range 20-100 $\mathrm{nm}$ and the predominant pore size was around $40 \mathrm{~nm}$.

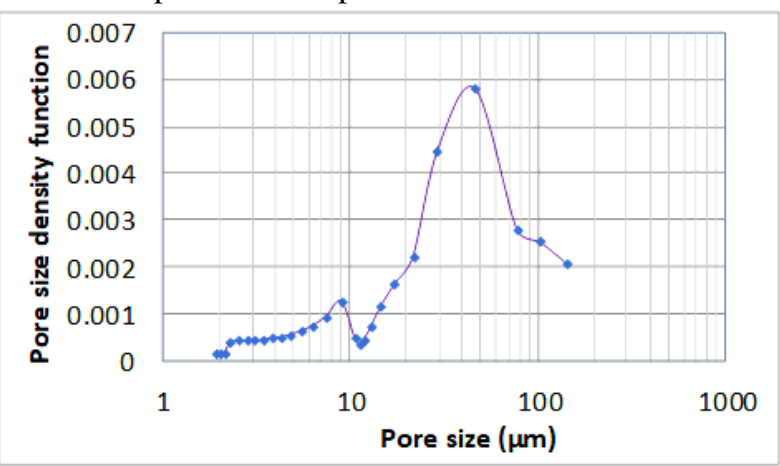

a) $\operatorname{HSF}(\mathrm{SC})$

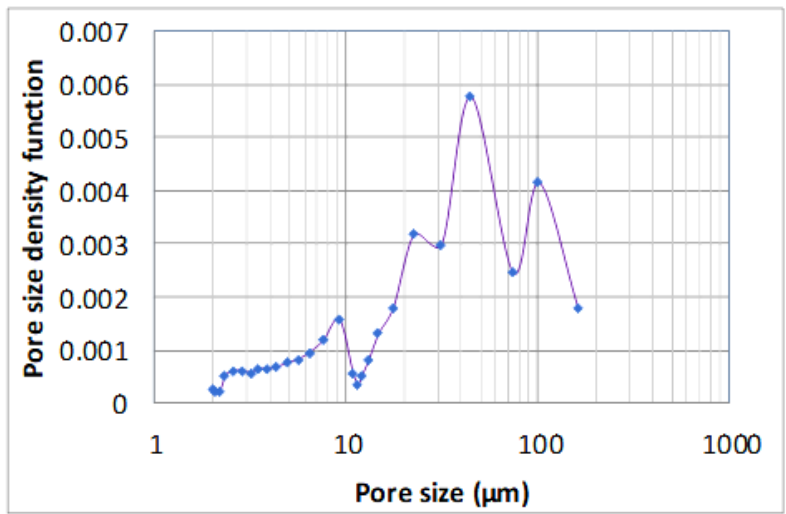

b) DVH2 (SC)

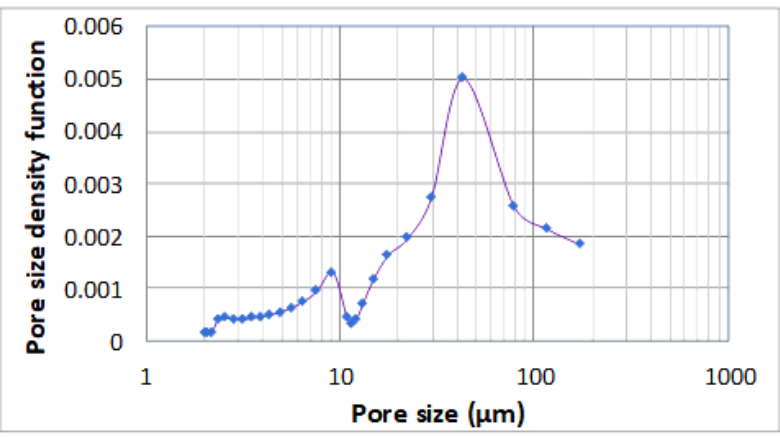

c) $\mathrm{CC}$

Fig. 2. Pore size density (PSD) function of soil samples HSF and DVH2 at natural states (SC) and with cultivation (CC).
Figure 3 shows a plot of the cumulative specific surface areas and pore sizes by BJH model for adsorption and desorption of soil samples without cultivation. The maximum value of specific surface area, $10.14 \mathrm{~m}^{2} / \mathrm{g}$, was found for the sample HSF using the adsorption branch, being slightly higher, $13.45 \mathrm{~m}^{2} / \mathrm{g}$, for the desorption branch. These values were found higher for the sample DVH2: $13.25 \mathrm{~m}^{2} / \mathrm{g}$ (adsorption) and 16.69 $\mathrm{m}^{2} / \mathrm{g}$ (desorption). They are relatively low and could be related to some geotechnical properties, such as liquid and plastic limits. However, the comparison of the same set of data with cultivation shows that the cumulative specific surface area was $10.45 \mathrm{~m}^{2} / \mathrm{g}$ (adsorption) and $13.36 \mathrm{~m}^{2} / \mathrm{g}$ (desorption) when the pore size is around 2 nm (Fig. 3). Then, if the pore size decreases, the specific surface area also decreases.

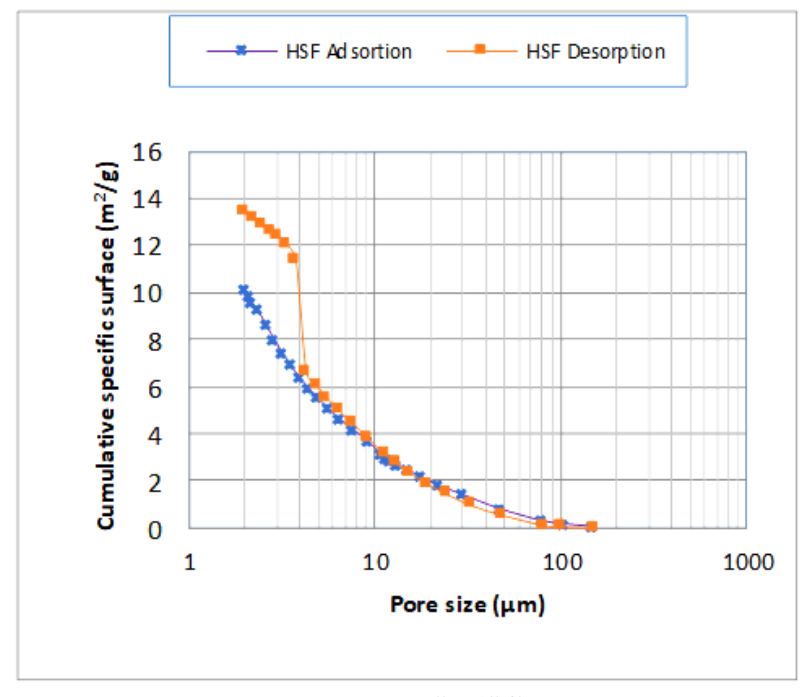

HSF (SC)

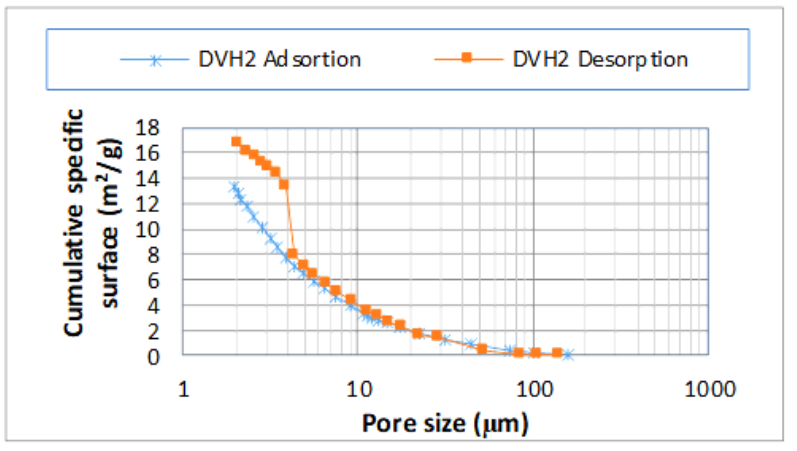

DVH2 (SC)

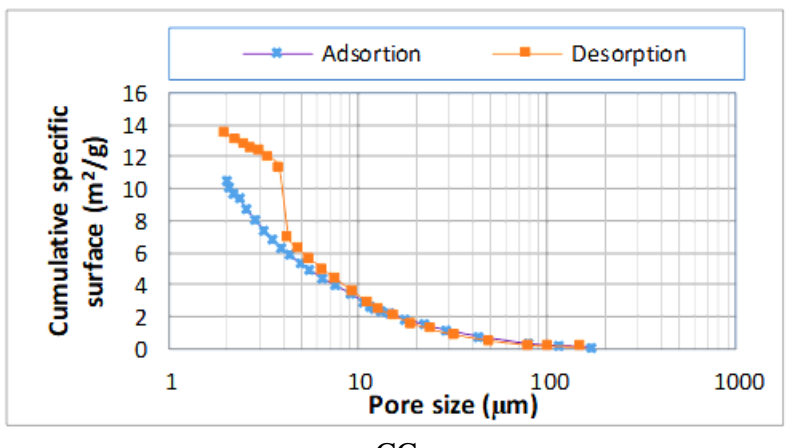

$\mathrm{CC}$

Fig. 3. Evolution of the cumulative specific surface with pore size by BJH adsorption and desorption of samples at natural states (SC) and with cultivation (CC). 


\subsection{Textural analysis by determination of plasticity and particle size}

The evolution of Atterberg limits, including the classification of the soil in the Unified Classification of Casagrande (UCC) is presented in Table 3. It can be observed that the plasticity of the soil decreased after the cultivation of vetiver. The plasticity index is $7.9 \%$. These results allowed classify this soil as sand-lime, mixtures of sand-lime, or sand-gravel-lime with fair plasticity, according to the UCC. It was of interest to estimate the plasticity index (IP in Table 3) using BET and Langmuir specific surface areas, following a previous method [27]. Thus, according to the results, the plasticity index calculated for the soil sample HSF and using the BET specific surface area $(11.68 \%)$ is the most approximate to the experimental value $(7.9 \%)$.

Table 3. Evolution of the Atterberg Limits and classification

\begin{tabular}{|c|c|c|c|c|c|c|c|c|}
\hline \multirow[t]{2}{*}{ Dates } & \multirow[t]{2}{*}{ Crop } & \multirow{2}{*}{$\begin{array}{l}\mathrm{LL} \\
(\%)\end{array}$} & \multirow{2}{*}{$\begin{array}{l}\text { IP } \\
(\%)\end{array}$} & \multicolumn{2}{|c|}{ IP BET $(\%)$} & \multicolumn{2}{|c|}{ IP Langmuir (\%) } & \multirow[t]{2}{*}{ UCC } \\
\hline & & & & HSF & DVH2 & $\mathrm{HSF}$ & DVH2 & \\
\hline $14 / 05 / 2014$ & No & 27.9 & 7.9 & 11.68 & 15.5 & 16.04 & 21.25 & \\
\hline 30/04/2015 & Yes & NP & NP & & & & & ML \\
\hline 08/06/2016 & Yes & NP & NP & & & & & ML \\
\hline
\end{tabular}

Note: $\mathrm{LL}=$ Liquid limit $\mathrm{IP}=$ Plasticity index IP BET= Plasticity index determined by the specific surface area of BET, IP Langmuir= Plasticity index determined by the specific surface of Langmuir, IP BET ó Langmuir $=0.54 \mathrm{Ase}+0.0874 \mathrm{p}$ where: Ase $=$ Specific surface area, $\mathrm{p}=$ Mineral content of clay in soil.

On the other hand, the experimental results of particle size analysis (Table 4) of the selected samples show a predominated sand fraction (67.38 wt. \%), followed by the clay fraction $(25.16 \mathrm{wt}$. \%) before cultivation. Figure 4 shows the variation of these results. Variations of texture of the soil at $1 \mathrm{~m}$ or superficial sampling can be observed, although they are not significant except the percentage of gravel in a sample taken with the record 6/12/2015. Some slight variations can be observed according to these results, with variations in clay content in the range 25 (without cultivation) - 33.5 (with cultivation, after 30 months). Gravel and sand percentages presented more variation.

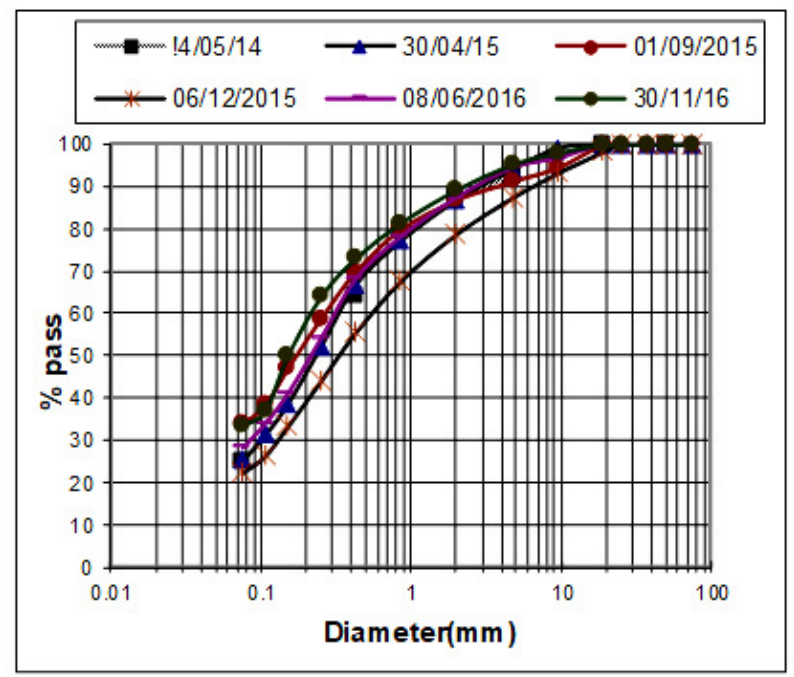

Fig. 4. Evolution of the granulometry of the soil with Vetiveria's development.
Table 4: Experimental results of particle size analysis.

\begin{tabular}{|c|c|c|c|c|c|}
\hline Dates & Crop & Depth & $\begin{array}{c}\text { Gravel } \\
(\text { wt. \%) }\end{array}$ & $\begin{array}{c}\text { Sand } \\
(\text { wt. \%) }\end{array}$ & $\begin{array}{c}\text { Clay } \\
(\text { wt. \%) }\end{array}$ \\
\hline $14 / 05 / 2014$ & No & Superficial & 7.46 & 67.38 & 25.16 \\
\hline $30 / 04 / 2015$ & Yes & $1 \mathrm{~m}$ & 5.87 & 68.76 & 25.37 \\
\hline $1 / 09 / 2015$ & Yes & $1 \mathrm{~m}$ & 8.84 & 57.36 & 33.8 \\
\hline $6 / 12 / 2015$ & Yes & Superficial & 12.48 & 65.17 & 22.35 \\
\hline $08 / 06 / 2016$ & Yes & Superficial & 5.64 & 66.08 & 28.28 \\
\hline $30 / 11 / 2016$ & Yes & Superficial & 4.77 & 61.74 & 33.48 \\
\hline
\end{tabular}

\subsection{Cohesion and internal friction angle}

Figure 5 includes the evolution of cohesion values and internal friction angle with vetiver root development. These geotechnical properties supported the previous results reported by Babosa and de Lima [28] of shear strength of different soils and slopes in Brazil covered with Chrysopogon zizanioides (vetiver).

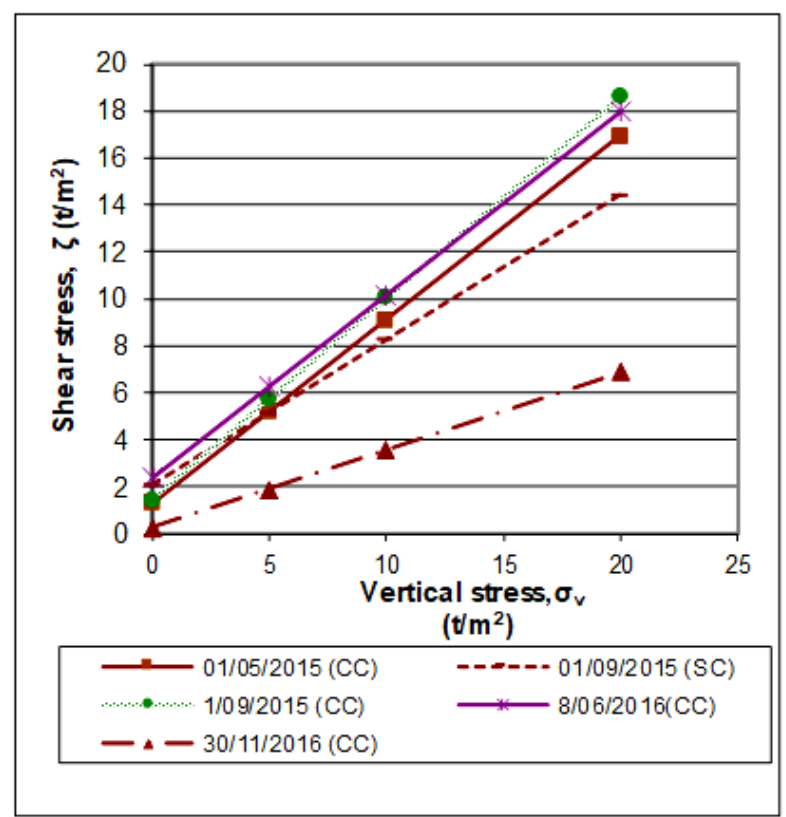

Note: $\mathrm{SC}=$ without cultivation $\quad \mathrm{CC}=$ with cultivation

Fig. 5. Shear strength of the soil in different intervals of time and development of vetiver.

According to the characteristics of the soils studied in the present work, it was found the presence of cohesion $\left(2.05 \mathrm{t} / \mathrm{m}^{2}\right)$ and an internal friction angle $\Phi=31.69^{\circ}$. After the plantation of vetiver, it was observed an increase of the internal friction angles $\left(40.63^{\circ}\right)$, and a decrease of the cohesion $\left(1.45 \mathrm{tn} / \mathrm{m}^{2}\right)$ (Table 5).

Table 5: Shear Strength values of the studied samples.

\begin{tabular}{|c|c|c|c|}
\hline Dates & Crop & $\begin{array}{c}\text { Internal } \\
\text { friction } \\
\text { angle } \\
\left(\boldsymbol{\emptyset}^{\mathbf{o}}\right)\end{array}$ & $\begin{array}{c}\text { Cohesion } \\
(\mathbf{C u}) \\
\left(\mathbf{T} / \mathbf{m}^{\mathbf{2}}\right)\end{array}$ \\
\hline $1 / 05 / 2015$ & Yes & 38.03 & 1.29 \\
\hline $1 / 09 / 2015$ & No & 31.69 & 2.05 \\
\hline $1 / 09 / 2015$ & Yes & 40.63 & 1.45 \\
\hline $08 / 06 / 2016$ & Yes & 37.97 & 2.37 \\
\hline $30 / 11 / 2016$ & Yes & 18.35 & 0.24 \\
\hline
\end{tabular}




\subsection{Infiltration analysis, fitting and modellization}

The infiltration measurements in the soil without and with cultivation of vetiver are presented in Figure 6 . The plot includes the fittings using the Kostiakov-Lewis model, using equation (1). Table 6 shows the fitted coefficients of the Kostiakov-Lewis equation for both the bare soil and the soil covered by vetiver, along with their coefficients of determination $\left(\mathrm{R}^{2}\right)$. Since these coefficients are found close to 1 , the experimental data fitted very well to this model.

The infiltration tests verified experimentally that the rate of infiltration of the terrain here studied was high, as expected because of its sandy texture. Then, it has been confirmed that the effect of planting vetiver on the infiltration of the soil was to reduce slightly its rate of infiltration. This result can be associated to an improvement of the structure of the soil and its compaction caused by the roots of the plant. This effect, along with the decrease of precipitation rate due to the interception of water by the plant canopy, may be effective for the protection of the slopes and the reduction of the erosion of the soil.

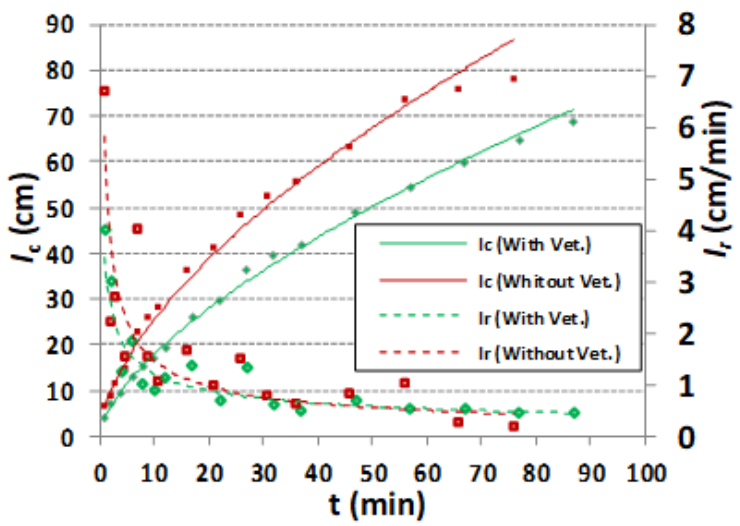

Fig. 6. Infiltration rate $\left(I_{r}\right)$ and cumulative infiltration $\left(I_{c}\right)$ curves for both the bare soil and the soil covered with Vetiveria.

Table 6. Values of the fitted Kostiakov-Lewis equation parameters and determination coefficients for both the bare soil and the soil covered with vetiver.

\begin{tabular}{|c|c|c|c|c|}
\hline Soil & $\boldsymbol{K}$ & $\boldsymbol{n}$ & $\boldsymbol{f}$ & $\mathbf{R}^{2}$ \\
\hline $\begin{array}{c}\text { With } \\
\text { vetiver }\end{array}$ & 4.6431 & 0.6077 & 0 & 0.9980 \\
\hline $\begin{array}{c}\text { Without } \\
\text { Vetiver }\end{array}$ & 7.9644 & 0.5391 & 0 & 0.9929 \\
\hline
\end{tabular}

\section{Conclusions}

This research examined the viability of applying Bioengineering tools to stabilize slopes and prevent the erosion caused by events of torrential rains. It was in connection with the problems associated to the climate change, with social and economic impacts, which are very difficult to be evaluated. To resolve these problems associated to a marked increasing of rain levels, the present study has been conducted. Results were presented of an experimental research work conducted with the aim of an analysis of the contribution of the plant vetiver in protecting the slopes. In these experiments, the plants were sown on slopes of selected grounds in Guatemala. First of all, the soils of these slopes were characterized.

The mineralogy of the soils, deduced from XRD, allowed the identification of quartz, iron oxides (hematite and maghemite), feldspars and frequent clay minerals, in particular kaolinite, illite and chamosite, and the amphibole riebeckite. It is the first report on the presence of riebeckite in soils at Guatemala. From this study, it was concluded that swelling minerals of the smectite group were not present.

Standard soil analysis methods were carried out to determine particle size analysis, $\mathrm{pH}$, electrical conductivity, soluble salts, gypsum and sulphates, calcium carbonate, organic matter and capacity of exchangeable cations. The results (Table 1) suggested that the soils are fairly acid, with absence of calcium carbonate and worthless salinity. The levels of organic matter range from normal to medium suggesting that they are very fertile soils for the development of vetiver. Geotechnical properties of the soils have been also determined: liquid and plastic limits, plasticity index (Atterberg, Table 2) and shear strength. Furthermore, the effects of the plant on some hydrophysical properties of the soils, in particular infiltration rate, have been assessed.

The particle size analysis of selected soil samples showed a predominant sand fraction (55-68 wt. \%) and a plasticity index of $7.9 \%$. These results allowed classify the soils as sand-lime, mixtures of sand and lime, or sand-gravel-lime according to the Unified Classification of Casagrande. The specific surface areas (BET and Langmuir models) ranged from 11.68 to $15.5 \mathrm{~m}^{2} / \mathrm{g}$ and the pore size (BJH method) ranged between $17-160 \mathrm{~nm}$. The accumulated specific surface areas were higher in the desorption branch.

It was found the presence of cohesion $\left(2.05 \mathrm{tn} / \mathrm{m}^{2}\right)$ and an internal friction angle of $\Phi=31.69^{\circ}$. After the plantation of vetiver, it was observed an increase of the internal friction angle $\left(40.63^{\circ}\right)$, a decrease in the cohesion $\left(1.45 \mathrm{tn} / \mathrm{m}^{2}\right)$ and the predominant pore sizes in the range $20-100 \mathrm{~nm}$ with a predominant pore size of $40 \mathrm{~nm}$.

The application of vetiveria in the slopes affected the infiltration characteristics of the soil. It has been performed an analysis of the experimental results on infiltration using the classical Kostiakov-Lewis model, with a mathematical fitting on an empirical exponential equation providing the coefficients of determination. From these results (Table 4), it can be concluded that the slope protected with this plant diminished its infiltration rate, being associated to the compaction caused by the plant roots.

Finally, it was concluded that all these results are of great application because demonstrated that the plantation of vetiver is effective to stabilize and prevent slopes from the erosion caused by severe rainfall events, being an interesting result from the point of view of Bioengineering. 


\section{Acknowledgements}

The financial support to this investigation from Universidad de San Carlos, Guatemala, is acknowledged. This research was funded by the Spanish Ministry for Science, Innovation and Universities program RETOS INVESTIGACIÓN under the project RIDESOST (AGL2017-85857-C2-1-R). Thanks are extended to the Regional Government of Junta de Andalucía Spain through Research Groups AGR 107 and TEP 204.

\section{References}

1. R.K. Sinha, S. Sinha, A. Grosh, Indian J. Environ. Prot. 25, 970 (2005)

2. J. Srivastava, J., S. Kayastha, S. Jamil, V. Srivastaba, Acta Physiol. Plant 30, 413 (2008)

3. P. Rotkittikhun, R. Chalyarat, M. Kruatrachue, P. Pokethitiyook, A.J.M. Baker, Chemosphere 66, 45 (2007)

4. N. Dudai, I. Tsion, S.Z. Shamir, N. Nitzan, D. Chaimovitsh, A. Shachter, A. Haim, J. Environ. Manage. 211, 247 (2018)

5. B. Yang, C.Y. Lan, W.S. Shu, Acta Ecol. Sin. 25, 45 (2005)

6. L.T. Danh, P. Truong, R. Mammucari, T. Tran, N. Foster, Int. J. Phytoremediat. 11, 664 (2009).

7. J.H. Rivera-Posada, J.A. Sinisterra-Reyes, V Congreso Nacional de Cuencas Hidrográficas, Santiago de Cali (Colombia), pp. 1-35 (2005)

8. R.G. Grimshaw, L. Helfer, L., A collection of papers and newsletters compiled by the Vetiver Network, World Bank Technical Paper, 273, 281 (1995)

9. E.W. Wilde, R.I. Brigmon, D.I. Dunn, M.A. Helkamp, D.C. Dagnan, Chemosphere 61, 1451 (2005)

10. O. Demirel, K. Demirel, K., J. Environ. Biol. 26, 409 (2005)

11. L. Robles-Austriaco, M.L.S. Luna, M.V. Tolentino, Proceedings of the Institution of Civil Engineers, Ground Improvement Part, 4, pp. 259-266 (2012).

12. S.B. Mckovski, L.P.H. van Beek, Plant Soil 324, 43 (2009)

13. M.S. Islam, H.M. Shahin, Geomech. Eng. 5, 313 (2013)

14. N.K. Srivastava, L.C. Ram, R.E. Masto, Ecol. Eng. 71, 479 (2014)

15. K.D. Balangood, F.M. Wong, T.D. Balangood, Aust. J. Bot. 63, 216 (2015)

16. A. Marañes, A.A. Sánchez-Garrido, AS. Haro, S. T. Sánchez, F.J. Lozano, Análisis de suelos, Editorial Copysur, Almería (1994)

17. K.S.W. Sing, D.H. Everett, R.A.W. Haul, L. Moscou, R.A. Pierotti, J. Rouquerol, T. Siemieniewska, Pure App. Chem. 57, 603 (1985)

18. F. Rouquerol, J. Rouquerol, K. Sing, Adsorption by powders and porous solids. Principles, Methodology and Applications, Academic Press, London, U.K. (1999)

19. E. Barret, L. Joyner, P. Halenda, J. Am. Chem. Soc. 73, 373 (1951)
20. ASTM D6913-04, Standard Test Methods for Particle-Size Distribution (Gradation) of Soils Using Sieve Analysis, ASTM International, West Conshohocken, PA, USA (2004)

21. ASTM D4318-05, Standard Test Methods for Liquid Limit, Plastic Limit, and Plasticity Index of Soils, ASTM International, West Conshohocken, PA, USA (2005)

22. ASTM D 3080-98, Standard test method for direct shear test of soils under consolidated drained condition, ASTM International, West Conshohocken, PA, USA (1998)

23. E. Young, Hydrol. Process. 5, 309 (1991)

24. A.M. Kostiakov, Int. Soc. Soil Science, $6^{\text {th }}$ Commission Transactions, Groningen Holland V. A., pp. 17-21 (1932)

25. M.R. Lewis, Trans. Amer. Geophys. Union 18, 361 (1937)

26. B. Dolinar, Appl. Clay Sci., 64, 34 (2012)

27. E. Garzón, P.J. Sánchez-Soto, Appl. Clay Sci. 115, 97 (2015)

28. M.C.R. Babosa, H.M. de Lima, Rev. Bras. Cienc. Solo 37, 113 (2013) 